\title{
Revista Brasileira de Enfermagem REBEn Formas de aprender na dimensão prática
da atuação do enfermeiro assistencial
}

\author{
Ways of learning in the practice of the attending nurse
}

Formas de aprendizaje en la práctica del enfermero asistencial

\section{Luciana Guimarães Assad}

Doutora em Enfermagem pela EEAN/UFRJ. Professora Adjunto do Departamento de Fundamentos em Enfermagem da Universidade do Estado do Rio de Janeiro (UERJ); Coordenadora Executiva do Curso de Enfermagem da Universidade Estácio de Sá; Enfermeira do Hospital Universitário Pedro Ernesto Igassad@terra.com.br End.: Rua Gilberto Cardoso, 280/604 Leblon, Rio de Janeiro. CEP: 22430-070

Lídia de Oliveira Viana

Doutora em Enfermagem pela EEAN/UFRJ. Professora Adjunto do Departamento de Enfermagem Fundamental da Escola de Enfermagem Anna Nery. ligiaviana@bol.com.br ligia@eean.ufri.br

\section{RESUMO}

Este estudo que foi desenvolvido em um hospital universitário na cidade do Rio de Janeiro e objetivou identificar formas de aprendizagem na prática assistencial do enfermeiro na organização hospitalar. O suporte teórico foi derivado da contribuição de Donald Shön, Philippe Perrenoud e Patricia Benner. Trata-se de um estudo de caso com abordagem qualitativa cujos dados foram coletados por meio de entrevista semi-estruturada e grupo focal. $\mathrm{Na}$ análise de dados, aplicou-se a técnica de análise de conteúdo. Os resultados sugerem que, na instituição, predominam duas modalidades de aprendizagem: a) que traz à tona elementos de transformação e b) que favorece a reprodução. Os enfermeiros alternam esses modelos a partir de variáveis tais como: tempo de atuação na área, ambiente construído no trabalho e identidade pessoal.

Descritores: Educação em enfermagem; Gerência; Equipe de enfermagem.

\section{ABSTRACT}

This study was carried out in a university hospital in Rio de Janeiro. Its objectives were to identify the ways of learning in the practice of the attending nurse in the hospital organization. The theoretical support was based on the light of Shön, Perrenoud, and Benner. This is a case study with a qualitative approach, developed with a semi-structured interview and a focal group. The content analysis was done. The results suggest that in the hospital we find two learning modalities: learning that uses transformation elements and the one that uses the reproduction. We notice that nurses alternate these models taking as a starting point the following variables: how long they have been working in this field, the work atmosphere and the personal identity. Descriptors: Education, nursing; Management; Nursing team.

\section{RESUMEN}

Este trabajo fue desarrollado en el hospital universitario y tuvo la intención de identificar las formas de aprendizaje de la pratica asistencial del enfermero en la organización hospitalar. Se trata de estudio de caso en el que se utiliza un abordaje qualitativo u sus informaciones fueron obtenidos com entrevistas semi-estructuradas e con grupos focales. En la analisi de los dados fue aplicado la técnica de análise de contenido. Los resultados sugieren que en el hospital predomina dos modalidades de aprendizaje: a) la que hace surgir elementos de transformación e b) la que hace surgir elementos de repetición. Los enfermeros utilizan de forma alternada dos modelos a partir de variables: el tiempo de actuación en su profesión, el ambiente construido em su trabajo y la identidad personal.

Descriptores: Educación en enfermería, Gerencia; Grupo de enfermería.

Assad LG, Viana LO. Formas de aprender na dimensão prática da atuação do enfemeiro assistencial. Rev Bras Enferm 2005 set-out; 58(5):586-91.

\section{INTRODUÇÃO}

O presente estudo o qual traz como objeto as formas de aprendizagem desenvolvidas na dimensão prática da atuação do enfermeiro assistencial, foi desenvolvido em um hospital universitário do Estado do Rio de Janeiro.

Percebemos ao longo de nossas experiências que nem toda experiência resulta em aprendizagens automáticas. Uma rotina eficaz tem justamente a virtude de dispensar todo e qualquer questionamento. Assim, a experiência só será fonte de auto-informação, no sentido restrito de reforço àquilo que está funcionando bem. Essas afirmativas permitem concluirmos que depois de "aprender" a rotina daquele serviço, o profissional liga o "piloto automático" para a realização de suas tarefas, tornando-se um cumpridor das mesmas ${ }^{(1)}$. Transpondo essa formulação para o contexto da Enfermagem, pensamos que o núcleo de um movimento de mudança na nossa profissão encontrase na educação e, mais especificamente, na noção de aprender a aprender na prática, buscando 
instrumentos que auxiliem o enfermeiro, no decorrer de sua formação continuada, a transformar 0 ambiente de trabalho num laboratório de aprendizagem.

Para melhor compreensão de conceitos fundamentais à presente pesquisa, é importante explicitar o significado do termo formação, termo um tanto ambíguo que, no dia-a-dia de nossos debates entre enfermeiros, tende a ser empregado de forma restrita à graduação. No caso deste estudo, assumimos que a formação é um processo de desenvolvimento integral do indivíduo, ao longo da vida, objetivando 0 seu amadurecimento profissional e emocional. Devido a essas características, é um processo inacabado, que, de forma alguma, limitase à formalidade dos estudos e demais atividades realizadas no âmbito das instituições escolares. Nesse sentido, a formação expande-se para além da visão de escola, uma vez que o ser humano, também em sua dimensão profissional, está em permanente processo educativo. Apesar dessa compreensão, julgamos preferível utilizar formação contínua ${ }^{(1)}$.

Corroborando esse entendimento, caracterizamos a aprendizagem como aquela, coerente com a sua própria lógica, que leva o indivíduo a aprender sempre; já que sua inteligência não está limitada à estocagem reprodutiva, mas é capaz de reconstrução constante. É importante acrescentar que, no movimento de aprendizagem, co-existem 0 conhecimento teórico e a experiência prática. Não se pode esquecer que cada profissional traz a própria história, o próprio conhecimento intelectual e, portanto, evidencia maior ou menor facilidade em aprender nas diversas situações da prática. A união entre o conhecimento pessoal e a experiência no trabalho determina a escolha de ações e decisões ${ }^{(2)}$ Decorre do exposto que o enfermeiro não constrói conhecimentos somente por meio de estudos acadêmicos, mas também o estrutura através do seu dia-a-dia no trabalho, a partir da realidade. Ao transformar o saber teórico em prática assistencial, o enfermeiro está construindo novo conhecimento; ou seja, está refazendo o que havia aprendido, sob a perspectiva assistencial.

Através da experiência, o profissional constrói o seu conhecimento, definido como o conjunto de esquemas de pensamento e de ação de que dispõe. Esse processo determinará as suas percepções, interpretações e as direcionará na tomada de decisões que lhe permitirão enfrentar os problemas encontrados no trabalho ${ }^{(2,3)}$. Para que 0 conhecimento gere competências, é necessário que os saberes dos profissionais sejam mobilizados através de seus esquemas de ações, decorrentes de esquemas de percepção, avaliação e decisão, desenvolvidos na prática.

Quando nos deparamos com a interpretação de estudiosos, parece claro que muito se avançou no sentido de compreender as diferentes possibilidades de aprender e desenvolver o processo de formação ao longo da vida e também do exercício profissional. Porém, é forçoso admitir que, apesar desses avanços no plano teórico e dos movimentos de mudanças mundiais, a nossa atuação na área da educação continuada ainda ignora as fecundas oportunidades de aprendizagem, que podem constituir elemento de discussão e de reflexão, enquanto se trabalha. Geralmente, ainda nos concentramos na operacionalização deste propósito em situações episódicas, como cursos sobre temas pontuais que se reduzem a meros treinamentos para a equipe de Enfermagem, privilegiando-se a racionalidade técnica. Como assinalamos, caminhando em outra direção, faz-se necessário combinar teoria e prática e, desse modo, transformar 0 ambiente de trabalho em laboratório de aprendizagem, provendo-o de infra-estrutura para partilhar, construir e divulgar o conhecimento profissional.

Não queremos aqui ressaltar a prática como simples ativismo, em detrimento da teoria; o que defendemos é a necessidade de que não se subestime (ou ignore) um saber, ou uma área de conhecimento que contribui para a formação do profissional enfermeiro. Entender o trabalho como fonte de formação é compreendê-lo como parte da vida do ser humano e como estrutura que influencia a composição do ser, no plano individual, assim como o núcleo familiar, a escola ou outras instituições que venham a fazer parte de sua vida. A formação é um processo amplo e não se limita a simples desenvolvimento de aptidões e faculdades, mas tem uma amplitude que se refere a um "processo de construção e realização de um Eu em ascensão, esforçado em adquirir consciência do mundo e apreendê-Io em sua essência"(4). Esses argumentos teóricos reforçam a atualidade do objeto deste estudo, e direcionam o delineamento de nossos objetivos: identificar e descrever formas de aprendizagem na prática assistencial do enfermeiro na organização hospitalar.

\section{METODOLOGIA}

Trata-se de um estudo de caso de natureza qualitativa. Os atores sociais foram dezessete enfermeiros que desenvolvem atividades assistenciais. Para iniciar a investigação de campo, apresentamos 0 estudo ao Comitê de Ética da instituição para análise e parecer sobre autorização. Na coleta de dados utilizamos três procedimentos de pesquisa: questionário, entrevista individual semi-estruturada e grupo focal. No primeiro momento, empregamos questionários e entrevistas que subsidiaram o guia de temas para o grupo focal; no segundo momento, desenvolvemos grupo focal. Em respeito às indicações da literatura especializada, conduzimos os grupos focais como moderadora, e nessa condição, propúnhamos as questões para reflexão e debate entre os participantes e os estimulamos à livre manifestação. As perguntas abertas constituíam parte de um roteiro testado em um primeiro grupo focal-piloto, preparado a partir dos objetivos do estudo. O estudo respeita, em todos os seus aspectos, a Resolução n 196/ 96 sobre Pesquisa Envolvendo Seres Humanos. Respeitamos igualmente 0 anonimato dos participantes e dos setores mencionados por eles, optamos pelo uso de pseudônimos que traduzissem a nossa visão relativa à importância da educação formal ou informal na vida dos indivíduos. Eis porque atribuímos aos entrevistados nomes de pássaros brasileiros, buscando traçar uma analogia entre a liberdade do ato de voar com a liberdade e autonomia conquistada com a educação. Após o nome do pássaro, acrescentamos as siglas E ou GF para identificar a participação na entrevista, ou grupo focal, respectivamente. Para a análise, os dados foram agrupados em categorias, seguindo o método de seleção, categorização e discussão dos achados. Para suporte à análise utilizamos prioritariamente como referencial teórico, Donald Shön, Phillippe Perrenoud e Patrícia Benner.

\section{APRESENTAÇÃO DOS RESULTADOS:}

3.1 Aprendizagem com elementos de transformação pela movimentação entre teoria e prática

As formas de aprender têm como fator interveniente o tempo de experiência em determinada tarefa ou função. Quando principiante na profissão, ou no contato inicial com determinada situação nova, o enfermeiro busca modelos, numa tentativa de encontrar elementos de segurança que ajudem a reproduzir a rotina do serviço. Todavia, com 0 decorrer do tempo, ele encontra caminhos ou métodos que o auxiliarão na transformação daquela situação. Destaca-se em cinco níveis, as competências dos enfermeiros, a saber: novato, iniciante, competente, proficiente e especialista. O novato, enfermeiro principiante em determinada área, independente do tempo de graduado, é descrito, como profissional que, carente de experiência, busca aprender reproduzindo $0^{(5)}$. Num primeiro instante busca apreender regras, normas e rotinas do serviço. Somente com o tempo, ele terá subsídios para analisar e segurança para questionar qualquer situação no serviço, conforme podemos observar no relato a seguir:

Quando eu cheguei na Enfermaria $X$ a transfusão era feita gravitacional e você tinha muitos imprevistos, eu achei aquilo um absurdo,...comecei a pressionar para mudar para bomba infusora, só que o grupo não concordava e eu fui buscar na pesquisa...hoje, 


\section{trabalhamos de forma diferenciada.(Pavão/GF)}

Nesse relato, percebemos que o enfermeiro novato sentiu-se sensibilizado com a rotina de hemotransfusão usual no setor. Inicialmente, apesar da discordância, ele reproduzia a situação, porque não tinha subsídios para fazer propostas de mudança. Com a evolução de sua experiência, pode perceber mais claramente a situação. Da condição de novato, passou à de iniciante, competente, proficiente e especialista. A sua busca foi centrada na pesquisa, no Curso de Mestrado, onde conseguiu provar para toda a equipe a possibilidade de transformar o procedimento. Nesse sentido, utilizando-se de uma aprendizagem individual, conseguiu a mudança, que atingiu o plano coletivo. Esse relato sugere ainda que o elemento desencadeador da aprendizagem foi um problema detectado na prática, que atingiu a sensibilidade do profissional, o que nos possibilita reafirmar que a motivação para aprender emerge da prática e guarda profundas relações com a identidade do profissional.

Nesse contexto, o relato a seguir, emitido por uma enfermeira com dez anos de graduação, indica que através de estudos individuais, além da participação num grupo de estudos interinstitucional, ela conseguiu aprender novos conceitos que possibilitaram a transformação da prática. Segundo suas palavras:

Os doentes queixavam na infusão do quimioterápico, e aí eu comece a perguntar: porque não podemos colocar um cateter profundo? A chefe médica me respondeu que infectava muito, mas que tinha ouvido falar de um cateter novo na Instituição X. Liguei para a instituição $X$, falei com o enfermeiro e acabamos montando um grupo de estudos....e assim aprendi..Hoje passo cateter em todos os pacientes com indicação e não existe mais tanta queixa na hora da infusão.(Quero-quero/GF)

Apesar de serem principiantes na área onde estavam atuando, as duas enfermeiras dos relatos acima, ambas com dez anos de experiência na enfermagem e atuando num setor novo, utilizaram-se de experiências passadas de cuidado, para analisar e agir na situação atual. Essas situações se enquadram na área de conhecimento da prática da enfermagem que denomina de Paradigmas e Conhecimentos Pessoais; ou seja, a área de conhecimento clínico que permite ao enfermeiro ajustar idéias preconcebidas, não confirmadas na situação atual. A tensão gerada entre uma situação clínica específica e experiências pessoais anteriores norteia as ações e decisões que serão tomadas pelos enfermeiros ${ }^{(5)}$.

Contrapomos essa situação vivenciada por enfermeiros novatos, com o relato da atuação de enfermeiras especialistas em cirurgia cardíaca as quais, frente a um procedimento novo, puderam atuar prontamente e dentro dos padrões:

Quando recebemos o transplante, não tínhamos nada de teoria, mas nós atuávamos com a nossa prática de conhecimento do que é cirurgia cardíaca....depois do primeiro é que fomos a São Paulo, saber como acontecia e vimos que estávamos exatamente nos padrões, corretos no que estávamos fazendo... (Bem-te-vi/GF).

Transcorrido esse primeiro momento, elas foram buscar na teoria 0 refinamento do conhecimento acerca do novo procedimento:

...partimos na busca desse conhecimento novo com a chegada da prática....buscamos cursos, treinamento, congressos, literatura,...(Bem-te-vi/GF).

O enfermeiro especialista é aquele que não necessita mais contar com regras e manuais, para realizar uma ação correta e efetiva; ele tem intuição e lida com os diferentes problemas sem muito esforço; além do mais, recorre à teoria quando em contato com casos novos, ou em situações que não evoluem conforme 0 esperado(5). Nessa perspectiva, as experiências concretas guiaram as percepções e as ações dos enfermeiros especialistas e permitiram uma rápida compreensão da situação. É interessante salientar que, nos depoimentos acima, os enfermeiros utilizaram como um dos recursos para a aprendizagem a busca interinstitucional, o que demonstra a importância da prática como fonte de conhecimentos que poderão ser transferidos para outras situações e transformados em saber, a partir de sua aplicação, enriquecendo esquemas de ação e construindo novas competências. Partindo dessa linha de pensamento, entendemos que, quando 0 enfermeiro se sensibiliza com um problema presente no cotidiano profissional, ele sente motivação para aprender e transformar. Dessa forma, incrementa-se o seu envolvimento e compromisso, pois a busca nasceu de um desafio com que se deparou no cotidiano e, de uma forma ou de outra, a aprendizagem para a mudança irá ajudá-lo na solução do problema que mobilizou sua sensibilidade.

Outro aspecto a ressaltar diz respeito à questão da aprendizagem por intermédio do grupo. Trabalhar e aprender em equipe é uma das dez competências a serem atingidas pelos profissionais atuais. Sob esse enfoque, adquire relevo a tese de que "cooperar é um valor profissional". Nessa perspectiva analítica, o trabalho em conjunto tornase necessidade, mais vinculada à evolução do ofício do que a uma escolha pessoal ${ }^{(6)}$. Percebemos que no ambiente de trabalho, especialmente no caso específico da área de saúde, a influência desse grupo é extremamente forte na medida em que as decisões são partilhadas e a construção das tarefas são também coletivas. Desse modo, como podemos observar no relato a seguir, a aprendizagem, para ser transformadora depende, da modificação e mobilização desse grupo:

...se não fizer em grupo a coisa não sai da teoria, a prática é difícil por isso; a teoria é bela, mas implementar é fazer com que cada grupo, entenda... (Beija-flor/GF).

Os saberes elaborados em outros ambientes e construídos por outros só farão parte do repertório do profissional observador, quando forem mobilizados pelo mesmo e incorporados à sua rotina. Nesse processo de apropriação, os saberes combinam-se com representações e teorias pessoais que serão reinvestidas pela pessoa na ação( ${ }^{(7)}$. Nessa perspectiva, para que a aprendizagem se concretize, é necessário que o conhecimento construído através da pesquisa ou da busca interinstitucional, seja implementado na prática; em caso contrário, a prática só funcionou como fator motivador e determinante para a busca. O trabalho em equipe é uma tendência atual para aqueles que defendem a profissionalização dos ofícios; ou seja, uma evolução cada vez mais intensa e profunda para as práticas orientadas por objetivos gerais e uma concepção ética. Frente à complexidade e diversidade de problemas, os profissionais não podem mais se eximir de desenvolver competências associadas à capacidade de cooperação, na resolução dos problemas. Cooperar é "dividir as forças para que o todo seja mais forte que a soma das partes"(3). Nesse sentido, o trabalho em equipe não é mais uma conquista individual, pois representa uma nova cultura profissional, a cultura de cooperação $0^{(3)}$. Os enfermeiros percebem essa situação como importante como ficou claro no relato que transcrevemos a seguir:

Não é que a aprendizagem esteja no coletivo,... eu posso ter o conhecimento individual, mas não consigo transformar, se não trabalho no coletivo... (Pavão/GF).

Apesar da importância implementada pelo enfermeiro, percebemos que existem dificuldades no encaminhamento de propostas em grupo. A ação coletiva possui alguns paradoxos: ou nos identificamos com 0 grupo e aderimos às decisões comuns, mesmo as custas de sacrifício; ou seguimos nossas próprias preferências e deixamos de lado a solidariedade. A rigor, no trabalho em equipe reside a essência da aprendizagem com foco na transformação.

Nessa análise, sedimentamos a premissa de que a necessidade da aprendizagem nasce da prática e que leva o enfermeiro a buscar a 
teoria, devendo o mesmo retornar a prática para aplicar e incorporar esse conhecimento transformando-o em saber e construindo competências. Nesse ponto, nos sensibilizamos acerca da aprendizagem essencialmente na prática, sem a busca teórica, discutida na categoria a seguir.

3.2 Aprendizagem com elementos de transformação pela movimentação prática

Compreendendo o saber como conceito polissêmico, na formação do enfermeiro, deparamo-nos com a existência de diversos saberes acadêmicos, científicos e técnicos-mas pretendemos ressaltar os saberes próprios da profissão do enfermeiro; ou seja, aqueles provenientes da experiência pessoal, os quais, apesar de menos sistematizados e formalizados que os outros, precisam ser explicitados, para que possam contribuir na discussão sobre sua formação. Ao mencionar saberes práticos, temos em mente o conjunto de instrumentos aos quais os enfermeiros recorrem no dia-a-dia do exercício da profissão; isto é o conhecimento elaborado pelo próprio enfermeiro, a partir das experiências; um saber estritamente associado à intervenção.

O enfermeiro, aprendendo através da prática, descreve situações de informalidade na troca de informações, conhecimentos e saberes entre os profissionais. Esse tipo de aprendizagem parece ser uma modalidade rápida de aprendizagem e que atende à necessidade premente de atuar em determinadas situações, novas ou não. Assim sendo, aprendem não somente a cuidar de seus clientes, mas também as rotinas do setor, a política da instituição, as relações de poder existentes, dentre tantas competências e habilidades demandadas no seu cotidiano. Nesse caso, valorizam o relacionamento da equipe e, por conseqüência, a comunicação como elementos relevantes no processo de aprendizagem, visto que os saberes construídos por outros provocarão transformações pessoais ao serem incorporados ao repertório pessoal, que fica disponível para agir no futuro, como abordado a seguir:

..eu saí da graduação com pouca teoria, pouca prática e muito senso de disciplina...aprendi tudo com médicos e auxiliares de enfermagem..(Beija-flor/GF).

Os enfermeiros relatam situação específica, na qual a mudança na rotina de atendimento ao cliente no setor, promoveu a aprendizagem, por possibilitar maior entrosamento entre os membros da equipe.

Temos o protocolo de manipulação mínima, então ao mesmo tempo que cuido da criança, o médico e outros também trabalham; isso gera ajuda, trocas importantes....(Pavão/GF).

Aprendem também em grupo, a partir de discussões acerca de sua prática, mas têm dificuldades na manutenção dessa prática, devido à sobrecarga de atividades a serem desenvolvidas, como observado no relato a seguir:

Toda terça-feira, a gente fazia uma reunião com a equipe....era uma troca muito boa..mas descontinuou pela sobrecarga de trabalho...então tem que ter continuidade. (Andorinha/GF).

A aprendizagem, através da troca de informações entre os grupos favorece a socialização profissional, ajustando os efeitos da formação inicial e conferindo legitimidade àquilo que é aceitável no meio profissional. Dessa forma, confrontam-se experiências diversas e essa prática contínua favorece a evolução dos saberes, das competências e do habitus ${ }^{(3)}$. As discussões em grupo são formas legítimas de aprendizado, visto que, quando bem conduzidas, levam o profissional a teorizar a partir da própria prática, possibilitando desenvolver a capacidade de se ver atuar e também de perceber as suas próprias disfunções ${ }^{(1)}$. Além da troca de saberes, os enfermeiros aprendem observando, como se depreende do que segue:

Eu aprendi olhando e observando...vendo seus ídolos, você consegue aprimorar a sua assistência, seu conteúdo, tudo, até como gente,...até o ruim, porque você vendo o ruim, você coloca assim: Pôxa, aquilo ali nunca vou fazer...(Papagaio/E).

Percebemos nesse relato que a observação ultrapassou os limites de uma reprodução, uma vez que o enfermeiro reflete sobre o que está observando e não se limita à mera repetição do que observou. Em parceria, o enfermeiro aprende e transforma com fundamento numa relação dialógica com a equipe de enfermagem e de multiprofissionais. Nesse ambiente de integração, ele desenvolve a capacidade de retirar do dia-a dia situações de aprendizagem. 0 trabalho em equipe permite: animar o debate, introduzir novas idéias e contestar tradições; fazer com que os profissionais sintam vontade de romper com seu individualismo; influenciar o clima geral com mais otimismo e menos passividade frente ao sistema; auxiliar na resolução de alguns problemas e crises; impelir os chefes a avançar e facilitar descentralização dos poderes de gestão(1).

Os dados dessa categoria indicam que a aprendizagem orientada para a transformação, a partir da movimentação prática, envolve troca de informações entre os profissionais, além da observação, o que possibilita um ajustamento, com reflexão, as rotinas e modos de trabalhar, sem que isso signifique simples cópia do senso comum. Nesse movimento, a comunicação, a reflexão e a equipe são variáveis importantes para a aprendizagem. Em continuidade, passamos a discutir a aprendizagem por reprodução compreendendo essa modalidade como mais uma forma de aprender.

\subsection{A aprendizagem com elementos de reprodução}

Compreendemos a aprendizagem por reprodução como um modelo baseado na aplicação da técnica, do senso comum e da rotina nos cuidados realizados com os clientes. Percebemos essa modalidade especialmente entre enfermeiros recém-admitidos ou novatos, profissionais desmotivados para o trabalho ou entre aqueles que não foram sensibilizados durante a vida familiar, social, na graduação e no ambiente de trabalho a aprender refletindo.

$\mathrm{Na}$ aprendizagem prática, existe uma diferença entre o profissional novato e 0 experiente, em sua relação com a equipe. Enquanto 0 primeiro parece ajustar-se fortemente aos efeitos da formação inicial, legitimando aquilo que é aceitável no meio profissional, somente o grupo mais experiente é capaz de confrontar-se com outros colegas e, desse modo, favorecer a evolução de saberes e do habitus(3). Os dados reforçam a percepção de que, em início de carreira, os enfermeiros tendem, prioritariamente para a reprodução de modelos. Ao mesmo tempo foram identificados fortes elementos para a conquista do grupo que está sendo introduzido, além sensação de que era necessário ter que aprender tudo de novo que o setor oferece. Para ilustrar, transcrevemos o depoimento seguinte:

....aprendi observando o outro fazendo.....se tenho dúvidas: Ai meu

Deus conecto aqui ou ali? Aí você olha em outro que já está conectado...vamos olhar para ver....(Andorinha/GF).

Verificamos que o enfermeiro novato inicia suas atividades na assistência, aprendendo através da imitação, da observação e da busca de esclarecimento de dúvidas com perguntas aos colegas mais experientes, tendo em vista que:

Se o enfermeiro tem um modelo, que seria o mais próximo do ideal, ele poderá ser um bom profissional, agora se o espelho for um profissional distorcido, ele poderá ser mais um profissional distorcido.(Codorna/GF).

É interessante destacar que os recursos de aprendizagem por reprodução empregados na prática são, basicamente, os mesmos presentes na aprendizagem por transformação. A diferença repousa no fato de que, no primeiro caso, o enfermeiro não se propõe a desenvolver alguma forma de reflexão sobre a sua prática, enquanto que, no segundo modelo, a perspectiva analítica está presente. No 
caso específico da reprodução, o enfermeiro, mesmo aquele com maior experiência no Serviço, "liga o piloto automático" e se deixa levar pelas situações, sem levar a efeito qualquer tipo de reflexão sobre o cotidiano profissional. A esse respeito, é muito esclarecedor o relato transcrito a seguir:

Eu cheguei com a repetição imposta, não tinha como mudar...então me adaptei..mas isso não significa que trabalho sem amor e sem responsabilidade.(Atobá/GF).

Essa situação acontece porque o profissional não sabe exatamente como faz, ou como age e, no dia-a-dia, não tem razões prementes para tomar consciência desse fato. Tal inconsciência não é resultado de recusa ou de mecanismos de defesa, mas, sobretudo, de um inconsciente prático, um produto de esquecimento progressivo à mercê da formação de rotinas, ou de um desconhecimento de sempre, um simples efeito da impossibilidade e da inutilidade de estarmos permanentemente consciente de nossos atos e nossas motivações ${ }^{(3)}$ Esse inconsciente prático pode também ser compreendido como intuição e ser parte de uma das seis áreas de conhecimento prático do enfermeiro. A pré-condição para perceber uma situação como intuitiva extrapola o nível do conhecimento, uma vez que, essa área está relacionada com a vivência pessoal do profissional, que, ao mesmo tempo, é submetido à forte influência da cultura da região e do ambiente em que está inserido. Depreende-se do exposto que um recém formado não teve ainda oportunidades de desenvolver essa competência enquanto que o especialista teve essa percepção aguçada, no convívio cotidiano com o ambiente de trabalho(5), como podemos visualizar nesse depoimento:

...mesmo que você não tenha a teoria, existe um outro lado que é o da percepção..da intuição que você usa mesmo....isso vem da prática..(Sabiá/E).

A intuição assenta-se nas competências de obtenção de índices muito pontuais, associados a um conhecimento profundo da situação, em todas as suas especificidades ${ }^{(8)}$. O enfermeiro, transformando ou reproduzindo forma o habitus, que se forma, quer queiramos, ou não. Esse pressuposto traz à tona a importância da ambiência e do grupo, no processo de aprendizagem no ambiente de trabalho(1).

A reprodução está associada ao conceito de sobreaprendizagem, que significa a perda de oportunidade de auferir novos conhecimentos, no meio de trabalho, devido à ausência da reflexão. À medida que uma prática se torna repetitiva e rotineira, o saber resulta tácito e espontâneo; dessa forma, o trabalhador pode evoluir para se tornar um grande especialista na área ou desperdiçar oportunidades de pensar naquilo que está realizando e acomodar-se à idéia de que está sendo arrastado na direção de condutas e erros que não podem ser corrigidos. Essa situação de sobreaprendizagem poderá levar ao tédio e a rigidez no trato com os clientes ${ }^{(9)}$

Inferimos do exposto que o reconhecimento de que a rotina existe e que pode representar uma estagnação, caso não se adote qualquer atitude ou reflexão para compreendê-la, é um passo importante para que os enfermeiros possam minimizar a sobreaprendizagem na sua prática. Segundo depoimento dos enfermeiros:

Se a rotina e a repetição te pegar, deixa você sem vontade de mudar ou estudar; você faz tudo mecanizado...tem que tentar inovar e aprender mais(Sabiá/E).

A repetição, embora menos estimulante que a invenção permanente da vida, está no centro de nosso trabalho e de toda prática. O que resta saber é se uma tomada de consciência acompanhada de reflexão pode fazer com que assumamos as rédeas dessa parte de nós mesmos ${ }^{(1)}$. Os enfermeiros demonstraram que podem permanecer reproduzindo até que um elemento motivador desperte para a mudança:

Você passa determinados momentos de sua vida realmente adormecido,..aí você chega a um ponto e pensa:, se eu deixar a vida me levar, para onde ela está me levando? ai é que vem o click...e vem a motivação.(Bem-te-vi/GF).

A motivação para rever a prática é algo bastante singular e a transformação acontece a partir de uma necessidade de se valorizar mais e de ultrapassar o imediatismo da realização cotidiana das tarefas:

Eu trabalhava como "tarefeira". Com a minha separação passei a gostar mais do que era meu e mudei a história...não era pra ninguém era para mim.(Quero-quero/GF).

Essa tomada de consciência com relação à prática, ocorre sob a pressão dos fracassos e dos obstáculos encontrados pelos profissionais, sendo a causa da conduta de tomada de consciência de ordem extrínseca, como indicam os depoimentos apresentados ${ }^{(1)}$. Nem todo profissional chega a ponto de uma tomada de consciência, até porque esse processo não é fácil e gera esforço individual, além de constituir forma de identidade e de busca pessoal. Os seres humanos reúnem vontade de saber com a de não saber. A tomada de consciência apresenta riscos e o mais simples está relacionado a uma forma de desorganização das ações realizadas anteriormente( ${ }^{(1)}$.

Muitas vezes, nossa intenção está repleta de ambivalência, pois dominar melhor a prática, afirmar a identidade, ampliar conhecimentos e aumentar competências representam desafios. Esses propósitos demandam requisitos, como: tempo, dinheiro, esforços, renúncia paciência; superação de insegurança, fracassos, humilhações e tensões com 0 ambiente que nos rodeia. 0 custo intelectual só poderá ser assumido, se as satisfações esperadas forem suficientes no âmbito da auto-estima dentre outros aspectos ${ }^{(1)}$. Essa premissa é reforçada a seguir:

...quando você busca conhecimento, quando procura entender tudo que está acontecendo.....você no íntimo se sente realizado. (Bemte-vi/GF).

O corretivo para essa situação é a reflexão, pois, através da mesma, podemos criticar as compreensões tácitas que amadurecem em torno das experiências repetidas de uma prática especializada. Assim procedendo, torna-se viável conferir novo sentido a situações de incertezas e singularidades que viermos a experimentar ${ }^{(9)}$. Assim compreendida, a consciência profissional adquire novo sentido, ela também passa por um esforço contínuo de tomada de consciência sobre o modo de enfrentamento dos obstáculos existentes, e, nesses momentos, pensamos como podemos ser melhores enquanto compreendemos com mais clareza como agir e, assim, transformamos nossas práticas ${ }^{(1)}$. Existem alguns mecanismos de formação que são sugeridos como instrumentos susceptíveis de favorecer a tomada de consciência e as transformações do habitus. São eles: a prática reflexiva; a mudança nas representações e nas práticas; a observação mútua; a metacognição; a escrita clínica; a videoformação; a entrevista de explicitação; a história de vida; a simulação e o desempenho de papéis e a experimentação e a experiência ${ }^{(3)}$, que no momento não nos cabe discutir por fugirem aos propósitos do estudo.

\section{CONSIDERAÇÕES FINAIS}

A partir dos dados e categorias discutidos, entendemos que as formas de aprendizagem desenvolvidas na dimensão prática da atuação do enfermeiro assistencial, individual ou coletiva, combinam elementos de transformação, com elementos de reprodução do processo de trabalho, da relação com os clientes e com a equipe e de sua identidade profissional. Os elementos de transformação estão associados àquelas modalidades de aprendizagem nas quais a ênfase está na equipe, no diálogo compartilhado e no planejamento, estando o enfermeiro numa situação de controle da situação. Ficou evidente que os enfermeiros desenvolvem com maior freqüência essa forma de aprender, quando têm uma boa ambiência no trabalho, gostam de sua área de atuação e 
trabalham com maior autonomia. Os elementos de reprodução dizem respeito à aprendizagem através da aplicação de normas, rotinas e do senso comum, sem que o enfermeiro perceba que a situação está controlando suas ações; nesse caso, ele trabalha a partir dos problemas que vão surgindo no decorrer de seu dia-a-dia. Os dados confirmaram conclusões de outros pesquisadores, como Perrenoud e Shön, quando indicam que os profissionais inexperientes, bem como os que se encontram desestimulados em relação ao seu trabalho, ou militam em áreas nas quais não estabeleceram laços de compromisso e satisfação profissional tendem a adotar a postura reprodutivista de princípios, procedimentos e modos de agir no trabalho.

É interessante destacar que, em alguns casos, detectamos as duas tendências e modalidades de aprendizagem no mesmo profissional, assim como também distinguimos dois grupos de enfermeiros na instituição, a saber: a)comprometidos e interessados vivamente na mudança e b)mobilizados para a reprodução pura e simples. Diante desse dado de realidade, é compreensível que a aprendizagem aconteça individual ou coletivamente. Também ficou evidente nos resultados que características como o tempo de atuação na área, a ambiência no trabalho e a identidade do enfermeiro são determinantes da modalidade de aprendizagem desenvolvida e de seu crescimento profissional.

Os saberes constituem um conjunto de elementos elaborados e incluídos na bagagem intelectual dos indivíduos e grupos, derivados de sua observação e experiência e dos estudos. Por sua natureza, para serem internalizados, eles nascem da prática e devem ser utilizados na prática. Sob essa perspectiva de análise, durante toda a vida, construímos representações, levantamos e testamos hipóteses e derivamos conclusões, a partir de nossa interação com o meio. Em situação de trabalho, o enfermeiro toma decisões a partir dos saberes internalizados, construindo seus esquemas de ação; resultantes daquilo

\section{REFERÊNCIAS}

1. Perrenoud P.A prática reflexiva no ofício de professor. Profissionalização e razão pedagógica. Porto Alegre (RS): Artmed; 2002.

2. Perrenoud $P$. Ensinar: agir na urgência, decidir na incerteza. Porto Alegre (RS): Artmed; 2001.

3. Shön D. El professional reflexivo. Como piensam los profesionales cuando actúam. Barcelona (ESP): Paidós; 1998.

4. Freitag B. O indivíduo em formação: diálogos interdisciplinares sobre a educação. São Paulo (SP): Cortez; 1994.

5. Benner P. From novice to expert. Excellence and power in clinical nursing practice. California (USA): Addison-Wesley Publishing Company; 1984

6. Perrenoud P. Dez novas competências para ensinar. Porto Alegre que há de comum nas diversas repetições ou aplicações da ação. Quando mobiliza saberes para desenvolver seus esquemas de ação, dizemos que ele está construindo suas competências e desenvolvendo 0 habitus, interiorizado por um aprendizado de tentativas e erros. A decisão de buscar novas oportunidades de aprendizagem sofre influências do meio; porém, a movimentação para a aprendizagem é individual. Assim, além das situações de qualificação obtidas através de processos formais, em cursos, treinamentos e atividades análogas, 0 enfermeiro aprende observando, experimentando ações, dialogando com colegas, com os pacientes, com os profissionais de outras instituições e aplicando os saberes teóricos em sua prática.

Os dados que obtivemos no campo da investigação reforçam igualmente a tese de que a formação tem caráter contínuo e permanente, abarcando processos formais e informais. Nesse processo, o enfermeiro faz o movimento de prática-teoria-prática, precisando desenvolver a competência de aprender a aprender, a fim de dar conta das demandas e requisitos de evolução da profissão. Levando a sério esse dado de realidade, é crucial que os setores institucionais encarregados de promover, estimular e incrementar a Educação continuada valorizem 0 trabalho como centro privilegiado de aprendizagem.

Concluimos que o enfermeiro aprende a partir da prática, uma vez que a motivação para a aprendizagem surge de sua inserção no cotidiano das ações inerentes ao processo de cuidados na instituição hospitalar; aprende através da prática, porque é confrontando os conhecimentos e informações na realidade, coloca-se como ator, experimentando condutas novas e descobrindo soluções adequadas à situação; e finalmente aprende para a prática, pois se o ponto de partida do aprendizado está na ação, seu desfecho também o está, uma vez que o que fica interiorizado são os saberes aplicados na prática e que têm incidência direta sobre a sua vida profissional.
(RS): Artmed; 2000.

7. Altet M. As competências do professor profissional: entre conhecimentos, esquemas de ação e adaptação, saber analisar. In: Perrenoud P, Paquay L, Altet M, Charlier ET. Formando professores profissionais. Quais estratégias? Quais competências? Porto Alegre (RS): Artmed; 2001. [s.p.].

8. Carbonneau M, Hétu JC. Formação prática dos professores e nascimento de uma inteligência profissional. Perrenoud P, Paquay L, Altet M, Charlier ET. Formando professores profissionais. Quais estratégias? Quais competências? Porto Alegre (RS): Artmed; 2001. [s.p.].

9. Shön DA. La formación de professionales reflexivos: hacia um nuevo diseño de la enseñanza y el aprendizaje en las profissiones. Madri (ESP): Ministério de Educación y Ciencia; 1992. 